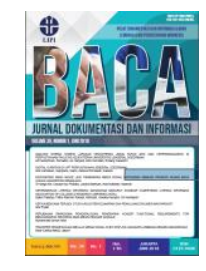

\title{
UPAYA PEMERINTAH INDONESIA MENGENDALIKAN BERITA PALSU
}

\author{
Arwendria ${ }^{1}$, Ariska Oktavia ${ }^{2}$ \\ ${ }^{1}$ Fakultas Adab dan Humaniora, UIN Imam Bonjol Padang \\ ${ }^{2}$ Fakultas Ilmu Pengetahuan Budaya, Universitas Indonesia \\ Korespondensi: arwendriadahlan@gmail.com
}

Diajukan: 12-02-2019; Direview: 20-02-2019; Diterima: 21-03-2019; Direvisi: 25-08-2019

\begin{abstract}
The aim of this study to gain an understanding of the government's efforts to organize and control fake news in the democratic era, especially ahead of the 2019 election. This research used the qualitative research methods, with a critical discourse analysis approach. Data was obtained from news texts published by online media during in 2018. Especially those containing fake news relating to general elections. Data collection used documentation techniques. The results showed that what was needed to control fake news were by making people healthy in cyberspace. The government must worked together with various organizations to disseminate and educate the public regarding content in cyberspace. In addition, the government have also set up a special institution which was tasked with overseeing the circulation of news on the internet and testing the truth.
\end{abstract}

\begin{abstract}
ABSTRAK
Penelitian ini bertujuan untuk memperoleh pemahaman tentang upaya pemerintah dalam menata dan mengendalikan berita palsu menjelang pemilu 2019. Penelitian ini menggunakan metode penelitian kualitatif, dengan pendekatan analisis wacana kritis. Data diperoleh dari teks berita yang dimuat oleh media online tahun 2018. Pengumpulan data menggunakan teknik dokumentasi. Hasil menunjukkan bahwa yang diperlukan untuk mengendalikan berita palsu yakni dengan membuat masyarakat bersikap sehat di dunia maya. Pemerintah harus berkerja sama dengan berbagai organisasi untuk melakukan sosialisasi dan edukasi pemanfaatan konten informasi di dunia maya. Selain itu, pemerintah juga perlu membentuk lembaga khusus yang bertugas mengawasi peredaran berita di internet dan menguji kebenarannya.
\end{abstract}

Keywords: Information Literacy; Media; Fake news; Goverment role

\section{PENDAHULUAN}

Pengendalian berita palsu menjadi tantangan bagi pengguna media dan khususnya lembaga pemerintah sebagai pembuat kebijakan dalam memperoleh informasi terpercaya. Hal tersebut disebabkan oleh lanskap media berita telah berubah secara dramatis selama beberapa dekade terakhir. Saat ini telah terjadi peningkatan luar biasa dalam media online dalam hal jurnalisme, media sosial, dan keterlibatan publik. Memeriksa berita secara online, baik melalui Google, Twitter, Facebook, surat kabar, dan/atau situs media lokal telah menjadi kebiasaan masyarakat. Apalagi berita online dapat diakses melalui smartphone dan aplikasi seluler, sehingga setiap orang dapat cepat mengikuti perkembangan berita di berbagai dunia.

Di era informasi, masyarakat selalu dikelilingi oleh informasi yang sebagian besar dapat diandalkan namun sulit diverifikasi. Banyak pemangku kepentingan di seluruh dunia telah menyuarakan keprihatinan tentang prevalensi mis-informasi dalam politik kontemporer, terutama karena karakter dan manifestasinya. Menurut Mele et al. (2017), mis-informasi memiliki ciri media berita tradisional dan seolah-olah melalui proses editorial. Kenyataan 
bahwa informasi yang salah dapat dengan cepat disebarkan, namun sulit untuk diperbaiki. Kemampuannya untuk memutarbalikkan kebenaran menjadi ancaman serius pada demokrasi.

Saat ini bangsa Indonesia akan memilih presiden dan wakil presiden. Semenjak tahun 1999, pemilihan pemimpin negara sudah dilakukan secara demokratis. Namun beberapa tahun belakangan, perbedaan antar-pendukung sudah mencapai titik kritis. Salah satu penyebabnya adalah maraknya bermunculan berita palsu. Sumber dan platform yang digunakan bervariasi. Aktornya juga beragam, mulai yang dibuat oleh politisi, media, hingga kelompok kepentingan lain yang disengaja.

Berita palsu dihasilkan oleh orang atau sekelompok orang, atau robot yang seolah-olah bertindak sebagai situs media sebenarnya, tetapi sebenarnya adalah akun palsu atau menyesatkan yang dirancang untuk menipu publik. Ketika kegiatan penyebaran informasi palsu dilakukan secara sporadis, terorganisir, dan sistematis, maka informasi palsu menjadi kampanye dis-informasi yang dapat berpotensi mengganggu kampanye dan tata kelola negara.

Seorang anggota Komisi I DPR RI mengatakan bahwa "berita hoax, bohong, propaganda, dan SARA akan kembali mewarnai dan terulang di pilkada serentak dan pemilu tahun 2019" (http://www.dpr.go.id/berita/detail/id/18481). Jumlah rata-rata hoax dalam sehari mencapai 3.500 kali dan diprediksi akan meningkat seiring dekatnya pelaksanaan pemilu legislatif dan presiden secara serentak pada April tahun depan (http://www.tribunnews.com). Data Kemenkominfo menyebutkan bahwa ada sekitar 800.000 situs di Indonesia yang terindikasi sebagai penyebar informasi palsu (https://kominfo.go.id).

Dirjen Aptika Kementerian Kominfo mengatakan bahwa "ada 40.000-an lebih website yang mengaku media online namun tidak terdaftar, sebuah media harus mengikuti regulasi yang dikeluarkan oleh lembaga yang berwenang, mengikuti kaidah jurnalistik dan syarat administratif (https://www.bbc.com)". Masyarakat tidak akan menyebarkan berita palsu jika legitimasi pemerintah kuat, namun jika legitimasi melemah, oposisi akan mengekspoitasi kerentanan itu dengan memproduksi hoax. Mengacu hal tersebut, pertanyaan kajian ini yaitu topik dan kata penting apa saja yang memuat informasi berita palsu, serta bagaimana upaya pemerintah mengendalikan informasi tersebut yang terkait dengan pemilu 2019?

\section{TINJAUAN LITERATUR}

\subsection{Berita Palsu}

Tidak ada definisi yang jelas tentang istilah berita palsu, meskipun pertama kali muncul di Amerika Serikat pada bagian akhir abad ke-19 (NATO, 2018). Berita palsu merupakan cara berpikir terhadap sifat dari berita nyata. Berita telah didefinisikan dalam sejumlah cara, mulai dari laporan suatu peristiwa terkini, menarik, dan signifikan (Kershner, 2005), suatu laporan peristiwa yang secara signifikan mempengaruhi orang (Richardson, 2007), sampai berita dramatis dari sesuatu yang baru atau menyimpang (Jamieson \& Campbell, 1997). Berita sering dilihat sebagai output kegiatan jurnalisme, bidang yang diharapkan menyediakan informasi yang independen, andal, akurat, dan komprehensif (Kovach \& Rosenstiel, 2007).

Kumar \& Shah (2018) mengkategorikan informasi palsu berdasarkan niat dan konten pengetahuannya. Informasi palsu berdasarkan niat penulis dapat diklasifikasikan sebagai misinformasi dan dis-informasi (Fallis, 2014; Hernon, 1995; Wardle, 2017). Mis-informasi merujuk pada penyebaran informasi palsu yang tidak disengaja, sedangkan dis-informasi mengacu pada penciptaan dan penyebaran informasi yang disengaja atau yang diketahui salah" (Wardle, 2017). Berdasarkan niat, informasi palsu dapat dikategorikan sebagai misinformasi, yang dibuat tanpa maksud untuk menyesatkan. Penyebab umum kesalahan 
informasi termasuk kesalahan penyajian atau distorsi informasi asli oleh pelaku, karena kurangnya pemahaman, perhatian, atau bias kognitif (Fallis, 2009; Skyrms, 2010). Sebaliknya, dis-informasi dibuat dengan maksud menyesatkan dan menipu pembaca (Fallis, 2014; Hernon, 1995).

Menurut Thomas (1986) informasi palsu dapat diklasifikasikan sebagai opini atau fakta. Informasi palsu berbasis opini mengungkapkan pendapat individu (baik secara jujur diungkapkan atau tidak) dan menggambarkan kasus-kasus yang tidak memiliki dasar kebenaran absolut. Pencipta opini secara sadar atau tidak sadar menciptakan opini yang salah sehingga berpotensi mempengaruhi opini atau keputusan pembaca. Motif dari jenis informasi ini menurut Pomerantsev \& Weiss (2014) adalah mempersulit pembaca dalam membedakan kebenaran dari informasi yang salah, dan membuat mereka percaya pada versi informasi yang salah. Jenis informasi palsu ini termasuk berita palsu, rumor, dan tipuan palsu. Jika berita mengacu pada informasi yang akurat dari peristiwa nyata (Kershner, 2005), kata palsu sering digunakan secara bergantian dengan kata-kata seperti salinan, tiruan, dibuat-buat, dan tidak otentik (Andrea, 2016). Ada dua cara mendeteksi web palsu, yaitu melalui situs spoof (meniru web yang ada) dan situs tipuan (tampilan web menipu - sebagai entitas komersial yang unik dan sah) (Abbasi et.al, 2010).

Menurut Budiman berita palsu adalah berita yang tidak benar disampaikan dari sebuah berita yang bersumber dari sebuah media yang resmi (https://mmc.kalteng.go.id/). Berita palsu mengacu pada informasi palsu atau propaganda yang diterbitkan dengan kedok sebagai berita otentik (https://www.webopedia.com). Definisi sempit yang serupa dari berita palsu diadopsi oleh The New York Times. Publikasi tersebut menggunakan istilah untuk merujuk ke cerita yang dibuat dengan maksud untuk menipu, sering diarahkan untuk mendapatkan klik (Tavernise, 2016) dan berniat untuk menipu pembaca tentang legitimasi konten. Misalnya, clickbaits (konten yang secara khusus dirancang untuk menarik lebih banyak perhatian dari para pembaca) dipandang sebagai penyebaran berita palsu oleh beberapa peneliti, sementara yang lain tidak (Chen, et.al, 2015). Berita satire juga dapat dikategorikan sebagai jenis berita palsu oleh beberapa peneliti (Rubin et.al, 2016), sementara yang lain tidak (Shu et.al, 2017). Ada juga perdebatan serupa tentang rumor, teori konspirasi, berita hyperpartisan dan hoax.

\subsection{Bentuk Berita Palsu}

Marino (2017) membedakan berita palsu menjadi enam jenis, yaitu: 1) fantasy fake, berita palsu yang sengaja dirancang untuk menghibur, seperti kisah dunia lain tentang penampakan Bat Boy dan Elvis dari Weekly World News, Enquirer, dsb.; 2) funny fake, berita palsu yang dirancang untuk menghibur; 3) fony fake, berita yang dirancang untuk mengerjai seseorang; 4) fallacious fake atau propaganda elite, berita yang menyesatkan dan hanya mencari sensasional; 5) flat fake atau propaganda kekuatan penuh, berita yang berpura-pura menjadi sindiran dan membuat orang mengeklik tautan tersebut; dan 6) falshivka fake atau propaganda de ruski, kabar palsu yang berasal dari Moskow.

Berdasarkan jenis kontennya, Parliamentary Office of Science and Technology (2017) membedakan berita palsu tersebut menjadi enam yaitu: 1) konten fabrikasi, konten yang sepenuhnya salah; 2) konten manipulasi, distorsi informasi atau citra asli, misalnya judul yang dibuat lebih sensasional, sering dipopulerkan clickbai'; 3) konten pemikat, peniruan sumber asli, misalnya menggunakan branding dari kantor berita yang sudah mapan; 4) konten menyesatkan, penggunaan informasi yang menyesatkan, misalnya dengan menghadirkan komentar sebagai fakta; 5) konten kesalahan koneksi, konten yang akurat secara faktual yang 
dibagikan dengan yang salah informasi kontekstual, misalnya ketika judul artikel tidak mencerminkan isi; 6) Satir dan parodi, menyajikan berita lucu tetapi palsu seolah-olah benar.

\subsection{Literasi Media}

Literasi media adalah seperangkat perspektif yang secara aktif digunakan untuk mengekspos diri ke media untuk menafsirkan makna pesan yang ditemui (Potter, 2005). Menurut Aufderheide \& Firestone (1993), literasi media adalah kemampuan untuk menjangkau pesan dalam berbagai bentuk, untuk dianalisis dan diteruskan. Literasi media tidak hanya tentang membaca pesan media individu, melainkan merupakan tindakan dalam pembuatan pesan dan proses penyampaian dengan menciptakannya (İnceoğlu, 2007).

Sebuah penelitian menunjukkan bentuk kebiasaan dari penggunaan media dan sosialisasi media untuk pengembangan kompetensi media. Konsensus kuat tentang perlunya kompetensi media untuk menggunakan media digital secara efektif dan potensi media digital sebagai media pembelajaran. Khususnya terkait dengan teknologi internet interaktif yang telah menjadi persyaratan baru di banyak bidang pekerjaan dan untuk mahasiswa di perguruan tinggi. Keterampilan dan pengetahuan yang diperlukan untuk menggunakan media digital sebagai sumber belajar dapat dikembangkan dalam pendidikan tinggi. Dalam masyarakat modern, kompetensi mengenai penggunaan media digital belum merata antara strata sosial dan lingkungan yang berbeda (Hertha \& Rott, 2014).

\section{METODE}

Penelitian ini menggunakan metode kualitatif. Penelitian ini menggunakan pendekatan interpretatif. Sumber data penelitian ini adalah teks wacana berita (bersifat tekstual). Teks berita media online selama tahun 2018 - berisi berita palsu yang berkaitan dengan pemilihan umum. Pengumpula data dilakukan dengan studi dokumentasi. Studi dokumentasi digunakan untuk mengumpulkan daftar media online yang telah diblokir pemerintah sampai tahun 2018. Data yang terkumpul kemudian diklasifikasi menggunakan pernyataan yang disampaikan oleh Parliamentary Office of Science and Technology (2017).

Data diolah dengan tahapan: (1) mengumpulkan informasi yang memuat berita palsu dari selruh media online yang diblokir pemerintah tentang pemilihan umum; (2) memilah, menganalisis, dan mendeskripsikan elemen kebahasaan yang diduga memiliki berita palsu tentang pemilihan umum; (3) melakukan analisis dan pembahasan mengenai berita palsu tentang pemilihan umum; (4) menyimpulkan hasil analisis. Analisis data menggunakan analisis wacana kritis atau critical discourse analiysis (CDA), untuk menemukan atau mengungkapkan berbagai makna yang dibagikan serta berkontribusi atau mewakili strukturstruktur sosial dan ideologi dari teks, ujaran atau bicara, dan gambar-gambar visual. Pada penelitian ini, analisis hanya dilakukan pada tingkat pilihan topik dan kata/kosakata.

\section{HASIL DAN PEMBAHASAN}

\subsection{Memerangi Berita Palsu}

Di Website Kementerian Komunikasi dan Informatika (https://kominfo.go.id/) diketahui ada 38 website yang diblokir oleh Kominfo sampai tahun 2018. Dari 38 website diketahui ada 26 website yang memuat konten "islam" dan "politik", dan 12 website memuat konten "politik" dan "umum". 
Tabel 1. Daftar Website yang Diblokir oleh Kominfo

\begin{tabular}{|c|c|c|c|c|c|c|c|c|}
\hline No. & Nama Website & Fabrikasi & Manipulasi & Peniruan & Menyesatkan & $\begin{array}{c}\text { Kesalahan } \\
\text { Koneksi }\end{array}$ & $\begin{array}{c}\text { Satir \& } \\
\text { Parodi }\end{array}$ & Jumlah \\
\hline 1 & abuzubair.net & & & & 1 & 1 & & 2 \\
\hline 2 & An-najah.net & 1 & & 1 & 1 & & & 3 \\
\hline 3 & Aqlislamiccenter.com & 1 & & 1 & 1 & & & 3 \\
\hline 4 & Arrahmah.com & & 1 & 1 & & 1 & & 3 \\
\hline 5 & beritaislam24h.com & & & & & 1 & & 1 \\
\hline 6 & bersatupos.com & 1 & 1 & & & & 1 & 3 \\
\hline 7 & bisyarah.com & & & 1 & & 1 & & 2 \\
\hline 8 & Dakwahmedia.com & & 1 & & 1 & 1 & & 3 \\
\hline 9 & dakwahtangerang.com & 1 & & 1 & & & & 2 \\
\hline 10 & Dakwatuna.com & & 1 & & & 1 & & 2 \\
\hline 11 & Daulahislam.com & 1 & & & 1 & & 1 & 3 \\
\hline 12 & Eramuslim.com & & & 1 & & & 1 & 2 \\
\hline 13 & Gemaislam.com & & & & 1 & 1 & & 2 \\
\hline 14 & gensyiah.com & 1 & & & & & & 1 \\
\hline 15 & Ghur4ba.blogspot.com & & 1 & & 1 & & 1 & 3 \\
\hline 16 & Hidayatullah.com & 1 & 1 & & 1 & 1 & & 4 \\
\hline 17 & islampos.com & 1 & & 1 & & 1 & & 3 \\
\hline 18 & izzamedia.com & & 1 & & & & & 1 \\
\hline 19 & jurnalmuslim.com & 1 & & & 1 & & 1 & 3 \\
\hline 20 & Kafilahmujahid.com & & & 1 & 1 & 1 & & 3 \\
\hline 21 & Kiblat.net & & 1 & 1 & & 1 & & 3 \\
\hline 22 & Lasdipo.com & 1 & & & & 1 & & 2 \\
\hline 23 & Lemahirengmedia.com, & & & 1 & 1 & & 1 & 3 \\
\hline 24 & lontaranews.com & 1 & & & 1 & & 1 & 3 \\
\hline 25 & media-nkri.net & 1 & & & & & 1 & 2 \\
\hline 26 & muqawamah.com & & 1 & & 1 & 1 & & 3 \\
\hline 27 & Muslimdaily.net & 1 & & 1 & & & 1 & 3 \\
\hline 28 & nahimunkar.com & 1 & & & 1 & & 1 & 3 \\
\hline 29 & nusanews.com. & & 1 & & 1 & 1 & & 3 \\
\hline 30 & Panjimas.com & & & 1 & 1 & 1 & & 3 \\
\hline 31 & portalpiyungan.com, & 1 & & 1 & & 1 & 1 & 4 \\
\hline 32 & pos-metro.com & 1 & 1 & & & 1 & 1 & 4 \\
\hline 33 & Salam-online.com & & 1 & & 1 & & 1 & 3 \\
\hline 34 & smstauhiid.com, & & & 1 & & 1 & & 2 \\
\hline 35 & suara-islam.com & 1 & & 1 & & 1 & & 3 \\
\hline 36 & suaranews.com & 1 & 1 & & & 1 & 1 & 4 \\
\hline 37 & thoriquna.com & & & & 1 & 1 & & 2 \\
\hline 38 & Voa-islam.com & & 1 & & 1 & 1 & & 3 \\
\hline \multirow{2}{*}{\multicolumn{2}{|c|}{$\begin{array}{c}\text { Jumlah } \\
\text { Persentase (\%) }\end{array}$}} & 18 & 14 & 15 & 19 & 22 & 14 & \multirow{2}{*}{102} \\
\hline & & $\mathbf{1 7 . 6}$ & 13.7 & 14.7 & 18.6 & 21.6 & 13.7 & \\
\hline
\end{tabular}

Berdasarkan Tabel 1 terlihat bahwa kebanyakan dari website di atas memuat berita palsu dengan judul artikel yang menarik. Akan tetapi, isi beritanya berbeda (koneksi yang salah), mengomentari berita tersebut seolah-olah sebagai fakta (menyesatkan), dan menyebarkan konten berita yang sepenuhnya salah (fabrikasi). Ada sebanyak 9 website yang masih dapat diakses kembali, yaitu an-najah.net, arrahmah.com, dakwatuna.com, eramuslim.com, islampos.com, panjimas.com, salam-online.com, smstauhiid.com, dan suara-islam.com.

Hasil survei Masyarakat Telematika Indonesia (Mastel) tahun 2018 diketahui bahwa saluran penyebaran berita palsu melalui situs web sebanyak $34,90 \%$. Penyebaran berita palsu tersebut jauh dibanding media sosial yang menempati urutan pertama $(92,40 \%)$ dalam menyebarkan berita palsu. Hal tersebut dapat dilihat pada Gambar 1. 


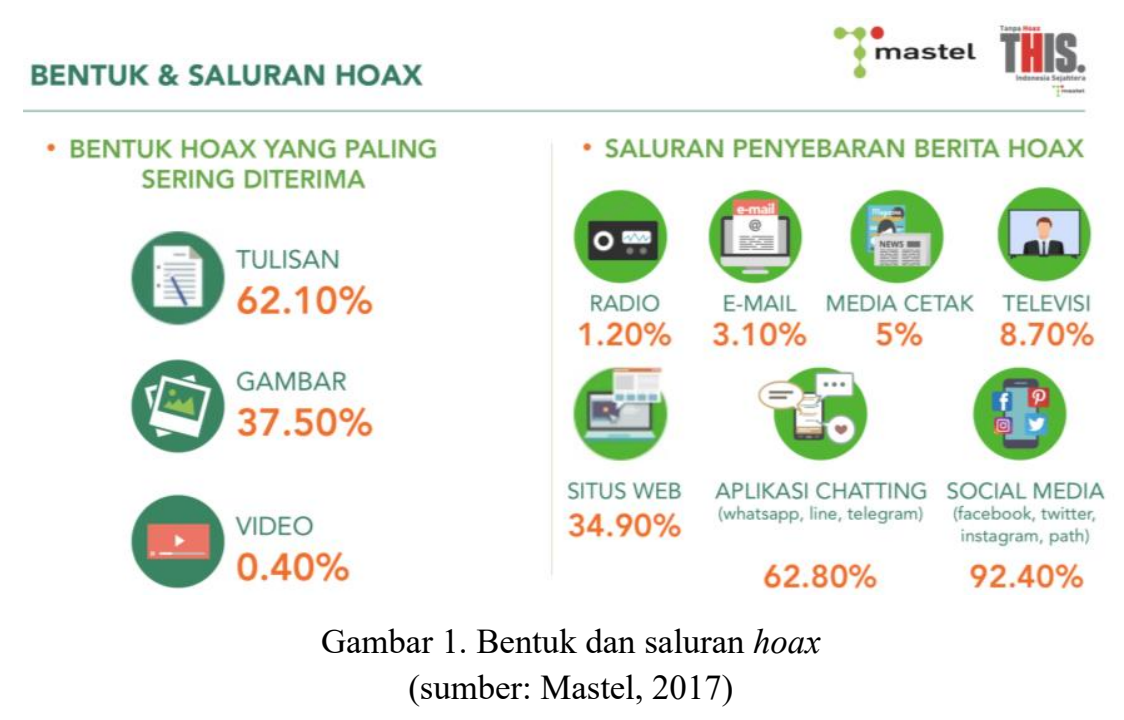

Platform yang paling populer sebagai media penyebaran berita palsu adalah Facebook. Berdasarkan hasil survei oleh DailySocial (https://dailysocial.id) sebanyak 81,25\% responden menerima berita palsu dari Facebook, diikuti oleh 56,55\% responden dari WhatsApp, dan 29,48\% responden dari Instagram. Dari hasil survei tersebut juga diketahui bahwa Twitter merupakan platform yang lebih aman (10,38\%) jika dibandingkan media sosial lainnya. Hal tersebut dapat dilihat pada Gambar 2.

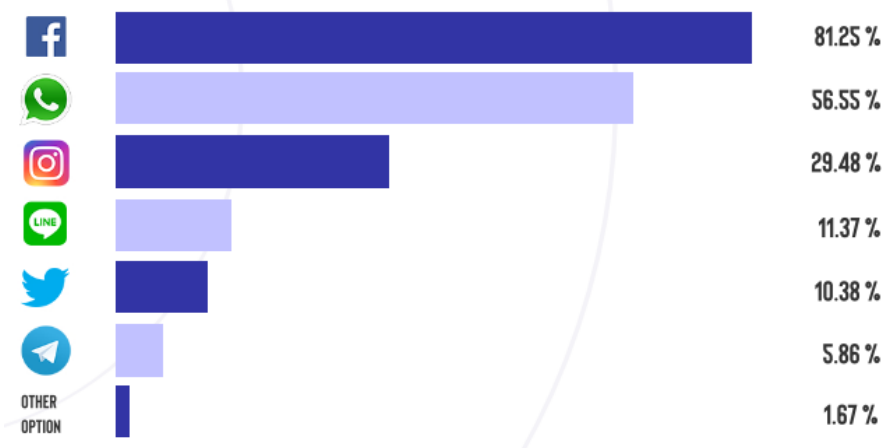

Gambar 2. Platform Media Sosial (Sumber: DailySocial)

Berdasarkan hasil survei Masyarakat Anti Fitnah Indonesia (Mafindo) tahun 2018 diketahui bahwa hoax dengan tema politik sejak Juli - Desember 2018 menyasar kepada Paslon 01 dengan 75 hoax (28,96\%), Pemerintah K/L 60 hoax (23,16\%), figur terkemuka 57 hoax $(22,01$ \%), Paslon 02 dengan 54 hoax (20,85\%), Parpol 9 hoax (3,48\%), Pemda 4 hoax (1,54\%). Isu atau berita palsu yang paling mendominasi, antara lain: (1) kekerasan pada oposisi yang dilakukan oleh pemerintah; (2) kegagalan pemerintah dalam tata kelola bahan pokok; (3) kebangkitan Partai Komunis Indonesia (PKI); (4) tenaga kerja asing; (5) telepon, WhatsApp, dan media sosial lain yang disadap pemerintah; (6) larangan adzan atau yang berkaitan dengan agama Islam; (7) bencana alam terjadi karena Jokowi; (8) Prabowo mempunyai utang sebesar Rp 17 triliun; (9) KPU, Polri, dan pemerintah tidak netral; 10) orang gila memiliki hak suara. 
Secara tekstual, teks-teks berita palsu tentang pemilu menunjukkan anti pemerintah atau figure seseorang. Hal ini dapat terlihat dari pilihan-pilihan kata yang dipakai, seperti: 'tidak becus', 'planga-plongo', 'perpecahan', 'rusuh', 'persekusi', 'potong tumpeng di atas lambang PKI', 'China segera kirim 3 juta warganya ke Indonesia', 'ancaman pembunuhan pada Anggota KPU', 'Kemendagri selundupkan', 'pendidikan agama Islam harus dihapus'. Katakata tersebut mengandung SARA dan bersifat provokasi. Hal tersebut sangat berbahaya jika dapat mempengaruhi orang lain ketika membacanya tanpa melakukan saringan terlebih dahulu.

Flynn, et.al (2017) \& Lewandowsky, et.al (2012) mengatakan bahwa memerangi misinformasi adalah tantangan yang sulit. Memerangi berita palsu di media sosial telah mengalami "perdebatan" dan kadang-kadang dapat mengurangi kepercayaan pada berita utama yang salah (Pennycook, Cannon, \& Rand 2017) dan kadang-kadang menciptakan efek "kebenaran tersirat" pada berita utama yang tidak berlabel sehingga lebih akurat (Pennycook \& Rand, 2017). Ecker, Lewandowsky, \& Tang (2010) menemukan bahwa peringatan khusus lebih efektif dari pada peringatan umum untuk mengurangi pengaruh terus-menerus dari paparan informasi palsu. Konsumen dapat menemukan berita palsu yang menarik dan akan mengunjungi halaman dengan berita palsu dan penulis akan dihargai melalui iklan yang ditampilkan di halaman tersebut (Stream SEO, 2012). Misalnya pada YouTube, ada iklan sebelum atau setelah video ditampilkan yang kadang-kadang mengganggu tampilan video.

\subsection{Peran Pemerintah}

Menertibkan dan memberantas berita palsu dapat dilakukan dengan berbagai cara, diantaranya melalui kampanye literasi, inisiatif pengecekan fakta, dan penetapan langkahlangkah hukuman untuk mencegah penyebarannya. Salah satu upaya pemerintah adalah melakukan kolaborasi preventif untuk mengurangi kemungkinan suatu peristiwa yang dapat memicu longsoran berita palsu. Upaya dari berbagai tingkatan yang ditujukan adalah mengurangi kemungkinan penyebaran informasi yang salah sebelum pemilihan umum dijadwalkan. Tujuan kolaboratif ini untuk mengurangi dampak penyebaran berita palsu (Dodda \& Dubbudu, 2019). Menurut Haciyakupoglu et al. (2018) bahwa kegiatan kolaborasi memiliki tujuan: (1) memfasilitasi pertukaran pengetahuan dan keterampilan; (2) mempersempit kesenjangan antara lokal dan global; (3) membantu mengidentifikasi masalah yang tumpang tindih antara berbagai masalah dan konteks; dan (4) memungkinkan pengiriman pesan yang konsisten.

Dalam menghadapi pemilihan umum, pemerintah Belgia melalui Superior Council for Media Education (SCME) of Wallonia-Brussels Federation, pada bulan Oktober 2017 selama dua minggu menyelenggarakan pendidikan media dengan topik berita palsu dan dis-informasi (Coche, 2018). Sebagian besar sekolah di Belgia mengajarkan siswanya tentang konsep berita palsu dan pentingnya membedakan antara informasi nyata dan palsu di media sosial. Hal yang sama juga dilakukan oleh berbagai negara di Eropa dan Amerika Serikat. Di Inggris, melalui lembaga terkait menyelenggarakan pendidikan dan bimbingan kepada warga negaranya tentang keterampilan informasi untuk membedakan antara informasi berupa fakta dan fiksi (The Digital, Culture, Media and Sport Committee, 2018).

Di Indonesia sejak tahun 2016, Kementerian Pendidikan dan Kebudayaan menggiatkan Gerakan Literasi Nasional (GLN) sebagai bagian dari implementasi dari Peraturan Menteri Pendidikan dan Kebudayaan Nomor 23 Tahun 2015 tentang Penumbuhan Budi Pekerti (http:/gln.kemdikbud.go.id/). Kementerian Pendidikan dan Kebudayaan membentuk 
kelompok kerja Gerakan Literasi Nasional untuk mengkoordinasikan berbagai kegiatan literasi yang dikelola unit-unit kerja terkait. Namun, gerakan tersebut lebih pada keterampilan membaca, menulis, berhitung, baik berbasis cetak maupun digital yang pada prinsipnya sudah menjadi tugas pokok dan fungsi dari Kemendikbud. GLN lebih ditujukan untuk gerakan membaca, bukan ditujukan untuk mahir menggunakan informasi. Gerakan membaca justru sudah mulai berevolusi menjadi literasi informasi sebagai gerakan jangka panjang yang telah dicanangkan oleh para pustakawan.

Pemerintah juga berkerja sama dengan berbagai organisasi untuk melakukan sosialisasi dan edukasi masyarakat terkait konten di dunia maya. Melalui Kementerian Komunikasi dan Informatika, pemerintah menggandeng Majelis Ulama Indonesia (MUI) untuk mengeluarkan fatwa MUI dalam rangka membantu pemerintah melaksanakan tugas sosialisasi literasi sesuai amanat dalam Undang-undang tentang Informasi dan Elektronik (UU ITE). Kemudian, MUI mengeluarkan fatwa Nomor 24 Tahun 2017 tentang Hukum dan Pedoman Bermuamalah melalui Media Sosial. Fatwa tersebut diharapkan dapat membantu pemerintah memberantas informasi palsu dan ujaran kebencian di media sosial (Bayu, 2017). Selain itu, pemerintah juga membentuk lembaga khusus yang bertugas mengawasi peredaran berita di internet dan menguji kebenarannya. Hal tersebut dapat dilihat Peraturan Presiden (Perpres) Nomor 133 Tahun 2017 tentang Perubahan atas Perpres Nomor 53 Tahun 2017 tentang Badan Siber dan Sandi Negara (BSSN), yaitu lembaga pemerintah berada di bawah Menteri Koordinator Politik, Hukum dan Keamanan. Namun, kini BSSN berada langsung di bawah Presiden.

\subsection{Solusi}

Literasi media baru dapat dilihat sebagai sebuah kontinum dari media "mengkonsumsi" ke media "prosuming". "Mengkonsumsi" literasi media mengacu pada kemampuan seseorang untuk mengakses pesan media dan menggunakan media pada berbagai tingkat kemahiran. Literatur sebelumnya tentang literasi media sangat menekankan pada keterampilan pengguna dalam menggunakan pesan media. Literasi media dipandang sebagai "kemampuan untuk mengakses, menganalisis, mengevaluasi, dan mengkomunikasikan pesan dalam berbagai bentuk" (Aufderheide \& Firestone, 1993). Kemajuan pesat teknologi informasi dan komunikasi membuat masalah akses tidak menjadi penghalang lagi. Keterampilan "mengkonsumsi" media telah diperluas menjadi mengakomodasi keterampilan yang lebih kritis dalam memproses informasi, seperti "sintesis" dan "kritik" (Frechette, 2005).

"Prosuming" literasi media mengacu pada kemampuan seseorang untuk menghasilkan konten media, di samping keterampilan yang dikonsumsi. "Prosuming" adalah gagasan yang pertama kali dikemukakan oleh Toffler (1980). "Prosumer" adalah produsen dan sekaligus konsumen yang "setengah dari produksi untuk disebarkan dan setengahnya lagi untuk digunakan sendiri" (Toffler, 1980). Prosumers dapat memproduksi sendiri produk media, dan mengambil keuntungan penuh dari teknologi baru. Prosumsi media memiliki dua aspek, yaitu membuat/memproduksi konten media (Goodman, 2005) dan berpartisipasi dalam penggunaan media (Jenkins, 2006). Misalnya, siswa dapat menggunakan alat media untuk membuat klip video dan mengunggahnya ke YouTube. Produksi melibatkan desain konten media yang selaras dengan ideologi individu, latar belakang budaya, dan tujuan yang ada. Aspek konsumsi terintegrasi dan tersirat dalam proses produksi. Misalnya, ketika pengguna lain mengomentari klip tertentu, pencipta mungkin harus membaca dan menginterpretasikan komentar dengan hati-hati sebelum ia merespon. Proses ini mirip dengan yang disebut oleh Thoman \& Jolls (2008) yakni partisipasi dalam penggunaan media. 


\section{KESIMPULAN}

Media daring yang memuat berita palsu menggunakan teknik koneksi yang salah, menyesatkan, dan fabrikasi. Kata-kata yang dipilih untuk mempengaruhi pembaca menunjukkan kebencian kepada pemerintah dan figure tertentu. Pemerintah telah berupaya melakukan berbagai kebijakan menyangkut penyebaran berita palsu tersebut melalui GLN, namun implementasinya bukan untuk meningkatkan keterampilan informasi masyarakat. Pemerintah juga perlu berupaya secara komprehensif dan berkelanjutan, yaitu dengan memberikan pendidikan tentang literasi media dan informasi. Pendidikan tersebut harus diperkenalkan sejak usia dini, mulai dari bangku sekolah dasar melalui penguatan kurikulum yang mengintegrasikan literasi media dan informasi pada setiap materi pembelajarannya hingga melakukan berbagai penyuluhan dan bimbingan yang dilakukan oleh perpustakaan pada berbagai tingkatan di daerah masing-masing. 


\section{DAFTAR PUSTAKA}

Abbasi, A., Zhu, Z., Zimbra, D., Hsinchun, C., \& Nunamaker, J. F. 2010. Detecting Fake Websites: The Contribution Of Statistical Learning Theory. MIS Quarterly, 34 (3), 435-461.

Andrea, M. (n.d.). Aesthetics of fake: an overview. Aisthesis, 9 (2), 59.

Aufderheide, P., \& Firestone, W. 1993. Media Literacy: A Report of the National Leadership Conference on Media Literacy. Queenstow, MD.

Bayu, D. J. 2017. Blokir Tak Efektif, Menkominfo Harap Fatwa MUI Berantas Hoax. Di https://katadata.co.id/berita/2017/06/10/blokir-tak-efektif-menkominfo-harap-fatwa-muiberantas-hoax.

Chen, Y., Conroy, N. J., \& Rubin, V. L. 2015. Misleading Online Content: Recognizing Click Bait As 'False News'. In Proceedings of the 2015 ACM on Workshop on Multimodal Deception Detection. Seattle, Washington, USA: ACM.

Coche, E. 2018. Fake News'and Online Disinformation: Case Study - Belgium. Amsterdam: Institute for Information Law (IViR) Amsterdam Law School University of Amsterdam.

Dodda, T. P., \& Dubbudu, R. 2019. Countering Misinformation "Fake News" In India: Solutions \& Strategies. New York: Factly Media \& Research (Factly) and The Internet and Mobile Association of India (IAMAI).

Ecke, Ullrich, K. H., Lewandowsky, S., \& T.W, T. D. 2010. Explicit Warnings Reduce But Do Not Eliminate The Continued Influence of Misinformation. Memory \& cognition, 38(8), $1087-1100$.

Fallis, D. 2009. A Conceptual Analysis of Disinformation. Proceedings of iConference.

Fallis, D. 2014. A functional Analysis of Disinformation. Proceedings of iConference.

Flynn, D. J., Brendan, N., \& Jason, R. 2017. The Nature and Origins of Misperceptions: Understanding False and Unsupported Beliefs about Politics. Political Psychology, 38 (1), $127-150$.

Frechette, J. D. 2005. Critical Thinking for the Cyberage. In G. Schwarz, \& P. U. Brown (Eds.), Media Literacy: Transforming Curriculum and Teaching (pp. 100-118). Massachusetts: Blackwell Publishing Malden.

Goodman, S. 2005. The Practice and Principles of Teaching Critical Literacy At The Educational Video Center. In G. Schwarz, \& P. U. Brown (Eds.), Media Literacy: Transforming Curriculum And Teaching (pp. 206-228). Massachusetts: Blackwell Publishing Malden.

Haciyakupoglu, G. 2018. Countering Fake News: A Survey of Recent Global Initiatives. Singapore: Nanyang Technological University.

Hernon, P. 1995. Disinformation and Misinformation through The Internet: Findings of An Exploratory Study. Government Information Quarterly, 12 (2), 133-139.

İnceoğlu, Y. (n.d.). Introduction of Media Literacy Course In Turkey's Curriculum. Di http://www2.mediamanual.at/themen/kompetenz/61 Inceoglu-Introduction-of-MediaLiteracy-Course-in -Turkeys-Curriculum.pdf (Retrieved October 17, 2018).

Jamieson, K. H., \& Campbell, K. 1997. The Interplay Of Influence: News, Advertising, Politics and The Mass Media. Belmont: Wadsworth.

Jenkins, H. 2006. Convergence Culture: Where Old and New Media Collide. NY: New York University Press.

Kershner, J. W. 2005. The elements of news writing. Boston, MA: Pearson Allyn and Bacon. 
Kompas. 2017. Akui Blokir Situs Tak Efektif, Pemerintah Ubah Strategi Perangi "Hoax". Di https://nasional.kompas.com/read/2017/02/02/10494811/akui.blokir.situs.tak.efektif.pemerin tah.ubah.strategi.perangi.hoax.

Kompas. 2018. Jokowi Teken Perpres, Badan Siber Nasional Langsung di Bawah Presiden. Di https:/nasional.kompas.com/read/2018/01/02/17103991/jokowi-teken-perpres-badan-sibernasional-langsung-di-bawah-presiden.

Kovach, B., \& Rosentiel, T. 2007. The Elements of Journalism: What News People Should Know And The Public Should Expect. New York: Three Rivers Press.

Kumar, S., \& Shah, N. 2018. False Information on Web and Social Media: A Survey. ArXiveprints, 1 (1), 1-35.

Lewandowsky, S., Ecker, U., Seifert, C. M., Schwarz, N., \& Cook, J. 2012. Misinformation and Its Correction: Continued Infuence and Successful Debiasing. Psychological Science in the Public Interest, 13, 106-131.

Marino, M. C. 2017. Fake News, A Look Back and I Made You Look. Di https://medium.com/thefake-news-reader/fake-news-a-look-back-and-i-made-you-look-294e0560a234 (Retrieved October 17, 2018).

Mele, N., Lazer, D., Baum, M., Grinberg, N., Friedland, L., Joseph, K., et al. 2017. Combating Fake News: An Agenda for Research And Action. Di https://www.hks.harvard.edu/publications/combating-fake-news-agenda-research-and-action (Retrieved October 17, 2018)

NATO Strategic Communications Centre of Excellence. 2018. Fake News: A Roadmap. The King's Centre for Strategic Communications (KCSC). London: Department of War Studies, King's College London.

Pennycook, G., \& David, G. R. 2017. The Implied Truth Effect: Attaching Warnings to A Subset of Fake News Stories Increases Perceived Accuracy Of Stories Without Warnings. Di https://papers.ssrn.com/sol3/papers.cfm?abstract_id=3035384 (Retrieved October 16, 2018).

Pennycook, G., \& David, G. R. 2018a. Lazy, Not Biased: Susceptibility to Partisan Fake News is Better Explained By Lack of Reasoning Than By Motivated Reasoning. Di https://papers.ssrn.com/sol3/papers.cfm?abstract_id=3165567 (Retrieved October 16, 2018)

Pennycook, G., \& David, G. R. 2018b. Who Falls For Fake News? The Roles of Analytic Thinking, Motivated Reasoning, Political Ideology, and Bullshit Receptivity. Di https://papers.ssrn.com/sol3/papers.cfm?abstract_id=3023545 (Retrieved October 16, 2018).

Pomerantsev, P., \& Weiss, M. 2014. The Menace of Unreality: How The Kremlin Weaponizes Information, Culture And Money. New York: Institute of Modern Russia.

Potter, W. J. 2005. Media Literacy. London: Sage.

Richardson, B. 2007. The Process of Writing News: From Information to Story. Boston, MA: Pearson Allyn and Bacon.

Schmidt-Hertha, B., \& Rott, K. J. 2014. Developing Media Competence and work-Related Informational Behavior In Academic Studies. International Journal on Advances in Education Research, 1 (1), 90-108.

Shu, K., Sliva, A., Wang, S., Tang, J., \& Liu, H. 2017. Fake News Detection on Social Media: A Data Mining Perspective. ACM SIGKDD Explorations Newsletter (19. 10.1145/3137597.3137600.).

Skyrms, B. 2010. Signal: Evolution, Learning, and Information. Oxford University Press. 
Stream SEO. 2012. 10 Best Google Adsense Alternatives (2018 edition). Di https://streamseo.com/best-google-adsense-alternatives (Retrieved August 17, 2018).

The Digital, Culture, Media and Sport Commitee. 2018. Disinformation and "Fake News": Interim Report (HC 363). Fifth Report of Session 2017-19, on 29 July.

The Parliamentary Office of of Science and Technology. 2017. Online Information and Fake News. Postnote. 559, July.

Thoman, E., \& Jolls, T. 2008. Literacy for The 21st Century: An Overview \& Orientation Guide to Media Literacy Education. In C. Malibu, Part 1. Center for Media Literacy.

Thomas, J. E. 1986. Statements of Fact, Statements of Opinion, and The First Amendment. California Law Review, 74 (3), 1001-1056.

Toffler, A. 1980. The Third Wave. New York: Morrow.

Wardle, C. 2017. Fake News. It's Complicated. Di https://medium.com/1st-draft/fake-news-itscomplicated-d0f773766c79 (Retrieved October 16, 2018). 